of the nebula will be reduced by the factor $(1-d \lambda / \lambda)$ because each quantum carries less energy, and also roughly by the same factor again because the weaker ultra-violet part of the spectrum is displaced into the photographic region (the correction from bolometric to photographic magnitude). If, on the other hand, the red-shift is due to an actual velocity of recession, then not only does each of the two previous effects reduce the brightness in the ratio $(1-d \lambda / \lambda)$, but also there is a reduction by a similar factor because the nebula is receding and fewer quanta reach the photographic plate per second. From counts of nebulæ made to five different apparent magnitudes, the numbers of nebulæ in each of the five corresponding spheres of increasing radius can be found, the radius of each sphere being given by the intrinsic luminosity of the average nebula and its apparent luminosity, corrected either by $(1-d \lambda / \lambda)$ for pure red-shift, or by $(1-d \lambda / \lambda)^{3}$ for red-shift interpreted as velocity of recession.

These counts indicate that, if the red-shift is due to velocity, then the number of nebulæ per unit volume must increase rapidly with increasing distance -a somewhat startling result; on the other hand, if the red-shift is not produced by a Doppler effect, then the counts indicate that the nebulæ are uniformly distributed over the sphere of 350 million light years radius which is within the range of the 100-inch reflector at Mount Wilson. While this particular result was not stressed by Dr. Hubble, he concluded by pointing out how the completion of the 200 -inch reflector will enable such counts and velocity determinations to be extended over a far larger volume of space, and will thus permit a definite interpretation of the red-shift, either as due to velocity of recession, or as due to some other yet unknown physical cause.

\section{Decrease of the Barn Owl in England and Wales}

$\mathrm{P}$

ECISE knowledge of the standing of particular birds in Britain should result from the increasing number of national censuses which have been initiated in recent years. Where the statistical information is thorough, it will form an invaluable basis of comparison with similar data gathered in future years; even where statistics have been dropped and reliance is placed upon the opinions of many observers scattered over a wide area, the consensus of opinion may still be a reliable guide to the fluctuations of the population.

Both kinds of information have been utilised in a census of the barn owl in England and Wales, made between May and December 1932, the results of which have been summarised by G. B. Blaker in an attractive pamphlet published by the Royal Society for the Protection of Birds. By making reasonable estimations in areas where direct information was not forthcoming, the author assesses the total breeding population of barn owls (Tyto alba) in England and Wales at 12,000 pairs. Non-breeding birds averaged one to every 50 square miles, so that the total adult population of barn owls in the summer of 1932 was about 25,000 individuals.

The absolute number is not so important as knowledge as to what relation it bears to that of former years, and here the statistics of one season, which contain no time element, cannot help. But putting one scrap of evidence regarding former conditions with another, Mr. Blaker has no difficulty in coming to the conclusion that the fears of those who suspected a serious decline in the numbers of the barn owl are justified. "From all districts in central and southern England the reports brought the same tale-fewer occupied nests than a few years ago. . . . In parts of Essex and Suffolk the decline was less marked, while in Devon and Cornwall the barn owl seems to be holding its own. Northumberland, Cumberland and Westmorland are the only counties to record an increase."

The decline in numbers over the greater part of the country appears to be no new thing : it has been noted for the last thirty or forty years. The disturbing point is that it has been speeding up during the last six years or so, until it has reached a point when, so far as the records can be interpreted, about four per cent of the population (or 1,000 birds) disappears annually; this, of course, over and above the annual wastage which would keep the population at a steady number.

Several factors contribute to the falling numbers of the barn owl. Nesting sites are fewer, partly because church authorities object to the occupation of towers and belfries by the ghostly 'cherubim', and fence the old nesting holes with wire entanglements; partly because modern barns with corrugated iron roofs do not offer openings like the 'owls' windows' of the old type. Food is probably more scarce since 'rat weeks' were instituted and the farmer has generally intensified his campaign against vermin. This has had a further effect in that the methods of destroying rats by poison has, the evidence indicates, resulted in the poisoning of owls which have devoured living but poisoned rats. Finally, there is the deliberate destruction of barn owls by people who should, but seemingly still do not, know better.

The author suggests, without definitely formulating the charge, that inefficiency of the Wild Birds Protection Acts is involved in the decline of the barnowl, but he states quite clearly the crux of this matter, namely, that it is in the administration of the law that the weakness, if any, lies. Were the critics of the present Birds Protection Acts to report the offences and insist with witnesses upon the prosecu. tion of the offenders (and they seem to be well supplied with instances of law-breaking), they would be making a contribution of value to the working of the law, and making no more of a contribution than the laws in question expect and make provision for them and other well-disposed citizens to make. But indeed, with regard to the barn owl, it is legitimate to ask whether the probability is that its present status would have been better or worse had there been no bird protection laws, and further why, if the law is a source of evil, the brown owl should have increased in numbers so enormously in the years when the barn owl has been declining ? J.R.

\section{University and Educational Intelligence}

Birmingham.-Mr. Stuart McDonald has been appointed lecturer in pathology in succession to Dr. F. W. M. Lamb, who has been appointed professor of forensic medicine at Cairo.

CAMbridge.-Dr. W. W. Watts has been appointed to represent the University at the centenary of the Edinburgh Geological Society on September 3-4. 